\title{
Redes colaborativas e a construção de alianças estratégicas a micro e pequenas empresas varejistas
}

\author{
Mara Raquel Fetter ${ }^{1}$ \\ José Eduardo Zdanowicz
}

\section{Resumo}

Este artigo traz os resultados de uma pesquisa sobre redes colaborativas e a construção de alianças estratégicas a micro e pequenas empresas varejistas, com o objetivo de analisar o processo de planejamento estratégico em micro e pequenas empresas que atuam em alianças ou redes na cidade de Três Coroas, no Estado do Rio Grande do Sul. Para tanto, foi identificado o setor varejista e evidenciada a importância das pequenas empresas para esse setor. A fim de ampliar o conhecimento sobre as redes colaborativas, no referencial teórico estão descritos alguns aspectos sobre cooperação e competição e relacionadas várias tipologias e configurações de redes existentes. Trata-se de uma pesquisa quantitativa, aplicada através de um questionário, com objetivo de demonstrar a percepção dos empresários em relação às redes em que atuam. A configuração é apresentada como uma alternativa competitiva para as micro e pequenas empresas, e vários aspectos evidenciam a importância do planejamento estratégico para essas empresas.

Palavras-chave: Redes Colaborativas. Planejamento estratégico. Alianças estratégicas.

\section{Abstract}

This article is related to a research on collaborative networks and building strategic alliances to micro and small retailers companies with the aim of analyzing the strategic planning process in micro and small enterprises that operate in alliances or networks in the city of Três Coroas in Rio Grande do Sul. On that purpose, it was identified both the retail sector and highlighted the importance of small businesses for this sector. In order to increase our knowledge about collaborative networks, some cooperation and competition aspects are described in the theoretical section and it was also related many types and configurations of existing networks. This is a quantitative research carried out through a questionnaire in order to demonstrate the

\footnotetext{
${ }^{1}$ Acadêmica do Curso de Administração das Faculdades Integradas de Taquara - FACCAT/RS. marafetter@aluno.faccat.br

${ }^{2}$ Professor das Faculdades Integradas de Taquara - FACCAT/RS. Doutor em Administração e Gestão Empresarial pela Universidade de León - Espanha. eduardoz@faccat.br
} 
perception of entrepreneurs in relation to the networks in which they operate. The configuration is displayed as a competitive alternative for micro and small enterprises, and many aspects show the importance of strategic planning for these companies.

Keywords: Collaborative Networks. Strategic Planning. Strategic Alliances

\section{Introdução}

As mudanças que vêm ocorrendo rapidamente no mercado levam os empresários a buscar estratégias diversificadas para obterem maior competitividade no mercado. Estratégias de colaboração, muito comuns no meio industrial, são uma alternativa também para empresas do ramo varejista. Há várias iniciativas de redes de cooperação entre essas empresas, entre elas podemos citar redes como Rede Fort, Farmácias Associadas, Agafarma e Rede Mundi.

As empresas varejistas são responsáveis pela venda de produtos diretamente aos consumidores finais, e as micro e pequenas empresas, além de serem o maior número de empresas no setor, são as que mais empregam, mais de $70 \%$ das pessoas no setor, o que demonstra a relevância das micro e pequenas empresas para esse setor. Neste artigo, são consideradas micro e pequenas empresas as que ocupam até 49 pessoas.

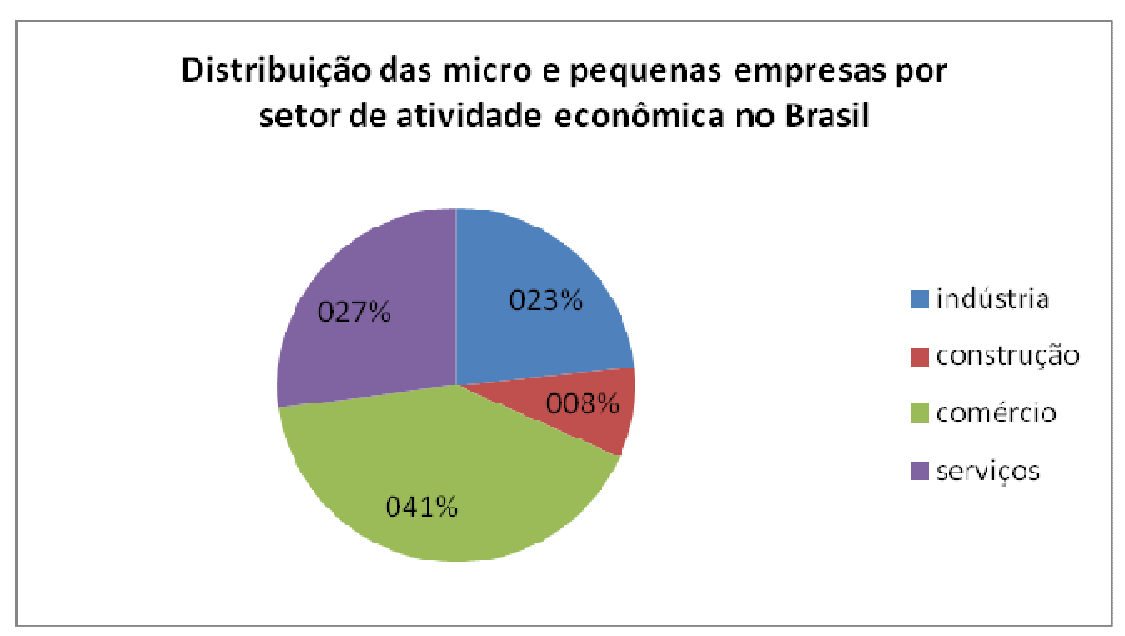


Gráfico 1: Distribuição das micro e pequenas empresas por setor. Fonte: Sebrae (2011) - Elaborado pelos autores

Pode-se observar, no gráfico 1, que mais de $40 \%$ das micro e pequenas empresas atuam no comércio, o que afirma a relevância da pesquisa sobre micro e pequenas empresas varejistas que atuam no modelo organizacional de redes de colaboração. Além disso, conforme classificação do IBGE (2012) são micro empresas as que ocupam até 19 pessoas, e pequenas empresas as que ocupam até 49 pessoas.

Apesar da relevância que têm na economia, as micro e pequenas empresas enfrentam muitas dificuldades no mercado, e as redes são uma alternativa para essas empresas superarem as dificuldades. Assim, o problema de pesquisa proposto é: qual é a importância do planejamento estratégico às micro e pequenas empresas varejistas que atuam no modelo organizacional de redes colaborativas e na construção de alianças estratégicas?

O principal objetivo do presente artigo é analisar o processo de planejamento estratégico em micro e pequenas empresas que atuam em alianças ou redes na cidade de Três Coroas no estado do Rio Grande do Sul. Busca-se também evidenciar a importância da gestão estratégica para micros e pequenas empresas que atuam em redes de colaboração. Busca-se demonstrar as vantagens e desvantagens para as organizações em estudo ao atuarem em redes de colaboração. Também se objetiva averiguar a percepção dos empresários quanto às redes em que atuam, em relação à interação entre os associados e quanto às estratégias adotadas pela rede. Além disso, pretende-se descobrir se a participação nas redes contribui para que as empresas alavanquem os resultados e a geração de caixa para a empresa.

Para melhor compreensão das redes colaborativas, será abordada a cooperação que possibilita ações colaborativas entre empresas e as tipologias de redes existentes. Buscaram-se, na literatura, as motivações para a formação de redes e os ganhos competitivos para as empresas que participam dessas redes. 


\section{Redes}

As redes colaborativas diferenciam-se de outros tipos de redes pois são formadas por empresas independentes que se unem a fim de atingir objetivos em comum. Nesta pesquisa, são consideradas redes de empresas que se encontram no mesmo nível da cadeia de valor.

\subsection{Cooperação e os relacionamentos interorganizacionais}

A cooperação é bastante discutida nos dias atuais, pois, apesar de o sistema capitalista prevalecer em nossa sociedade, há muitas iniciativas de cooperação no Brasil. Iniciativas de cooperação podem ser observadas tanto nas comunidades e bairros como também no meio empresarial.

A cooperação está presente nas comunidades desde os primórdios da sociedade. Desde o princípio, as pessoas cooperavam a fim de atingir um objetivo, como proteger o território, caçar, entre outros. Assim, as necessidades comuns das pessoas impulsionaram a cooperação entre elas.

Lago e Silva (2009) ressaltam que, apesar de essas organizações serem formas de organização primitivas, servem, nos dias atuais, como referência, uma vez analisados os objetivos centrais, a qualidade de vida dos associados e da comunidade.

Independentemente de onde for aplicada, a cooperação visa à melhoria da qualidade de vida dos envolvidos e da sociedade à qual pertencem. Iniciativas de cooperação no meio empresarial são cada vez mais comuns na economia mundial e brasileira. 
"O termo cooperação expressa o trabalho conjunto, numa perspectiva de aumentar a capacidade competitiva como meio de gerar benefícios para todos os envolvidos no processo" (SEBRAE, 2009, p. 9).

A cooperação visa trazer benefícios a todos os envolvidos, pois, através dela, as empresas podem aumentar a sua capacidade competitiva. Os relacionamentos interganizacionais que surgem através de ações de cooperação são importantes, uma vez que proporcionam maior competitividade para as empresas.

Os relacionamentos interorganizacionais podem ser analisados da mesma forma que os relacionamentos que ocorrem entre os países. Deve-se buscar a sobrevivência, não é favorável a uma país destruir o outro, mas sim buscar o que de melhor ele tem a oferecer (MINTZBERG; QUINN, 2001).

A cooperação entre as organizações ocorre quando há objetivos em comum, independente do segmento em que atuam e pode ocorrer entre grandes ou pequenas empresas, ou ainda entre ambas.

A cooperação vem sendo adotada por muitas empresas como estratégia competitiva. Ela pode se revelar uma melhor oportunidade no mundo dos negócios do que a individualidade. Para o Sebrae (2009), a cooperação surge como uma inovação na forma de competir, a fim de ganhar mercado, reduzir custos, exportar e importar, divulgar marcas, desenvolver tecnologias.

Para Castells (2005), a cooperação e as redes de empresas representam a única oportunidade para que as pequenas empresas dividam custos e riscos e tenham acesso a informações constantemente atualizadas.

O fato é que a cultura da cooperação vem ganhando espaço no mundo empresarial, uma vez que é uma estratégia para as empresas. Na literatura, há vários exemplos bem sucedidos de cooperação entre organizações. Amato Neto (2000) aborda as redes de pequenas empresas na Região da Terceira Itália, que, além de trazer benefícios para as empresas, impulsionaram o desenvolvimento da região. Já nos Estados Unidos, na região do Vale do Silício, também há exemplos de redes de cooperação semelhantes as da Itália, mas com o diferencial de atuarem em setores de alta tecnologia. Há ainda casos bem sucedidos de cooperação no 
Japão e na Alemanha. O interessante é que, em cada país, as redes são influenciadas pela cultura local, possuem diferenças, mas todas apresentam características de cooperação.

A cooperação motiva o desenvolvimento de vários relacionamentos interorganizacionais, muitas vezes com características semelhantes. As redes de colaboração e as alianças estratégicas são exemplos de relacionamentos que envolvem a cooperação. "Uma aliança estratégica entre duas organizações é um contrato de cooperação para atingirem um ou mais objetivos estratégicos comuns" (CRAVENS; PIERCY, 2007, p. 202).

Uma aliança estratégica é firmada entre empresas a fim de atingir um ou mais objetivos que as organizações têm em comum. Eiriz (2001), em seu estudo sobre alianças estratégicas, considera que pode não haver uma distinção teórica entre alianças estratégicas e uma relação de cooperação, tratando-se de nomes diferentes para uma mesma realidade.

Pode-se observar que esses relacionamentos envolvem cooperação em diferentes graus, dependendo dos objetivos pelos quais a rede ou a aliança está sendo desenvolvida.

\subsection{Tipologias de redes}

As redes como relacionamentos interoganizacionais são cada vez mais comuns. Pequenas, médias e grandes empresas configuram-se em redes para se tornarem mais competitivas no mercado.

Uma rede pode ser analisada sobre vários enfoques. Em sentido etimológico Kwasnicka (2006, p. 29), explica que "O termo rede é derivado do latim, e significa entrelaçamento de fios, cordas, cordéis, arames, com aberturas regulares fixadas por malhas, formando uma espécie de tecido".

As redes como relacionamento interorganizacional, no qual vários atores ou empresas se unem e coordenam atividades em conjunto a fim de atingir objetivos comuns é abordada por Grandori e Soda (1995, apud KWASNICKA, 2006, p. 30), para os quais as redes são "formas de organização da atividade econômica através 
de ações de coordenação e cooperação entre empresas, baseadas ou não em contratos formais, e se posicionam, do ponto de vista econômico, entre as empresas e os mercados".

"A arquitetura e composição das redes de empresas em formação em todo o mundo são influenciadas pelas características das sociedades em que essas redes estão inseridas" (CASTELLS, 2005, p. 253).

Essa postura do autor evidencia que não haverá uma rede igual à outra, cada uma delas é única, uma vez o ambiente no qual estão inseridas influencia em sua estrutura e funcionamento, naturalmente.

Ao abordar o assunto das redes, Wittmann, Dotto e Wegner (2008, p. 164) afirmam que "As redes de cooperação e alianças empresariais ocorrem em muitos setores e entre empresas de vários tamanhos, podendo envolver diferentes graus de cooperação e diversificando em relação aos propósitos e objetivos".

A abordagem desses autores reforça que as redes possuem características particulares. Observa-se que, mesmo sendo semelhantes, serão encontradas individualidades nas redes, fruto da sociedade na qual estão inseridas, dos objetivos que as empresas pretendem alcançar através da rede e até mesmo em relação ao tamanho das empresas envolvidas.

Serão apresentadas algumas tipologias de redes, essa classificação ajudará a compreender melhor as redes-alvo de estudo nesta pesquisa. Segundo Marcon e Moinet (2000, apud BALESTRIN; VERSCHOORE, 2008), as redes podem ser divididas em simétricas, assimétricas, formais e informais, conforme exposto a seguir.

As redes assimétricas possuem estrutura de poder centralizado, sendo adotadas por grandes empresas, a fim de se tornarem mais flexíveis e competitivas (BALESTRIN; VERSCHOORE, 2008). Nessas redes, as unidades são dependentes, todas devem seguir as estratégias definidas pelos gestores. Segundo Balestrin e Verschoore (2008), a relação nesse tipo de rede é semelhante à existente entre uma matriz e uma filial. 
Em relação às redes simétricas, o que as diferencia é a independência das empresas participantes, os quais coordenam certas atividades em conjunto a fim de atingir objetivos comuns.

Conforme entendimento de Balestrin e Verschoore (2008) a criação de novos mercados, suporte de custos e riscos em pesquisas e desenvolvimento de novos produtos, acesso à informação e à tecnologia, definição de marcas de qualidade, defesas de interesse, ações de marketing são alguns objetivos que as empresas buscam alcançar através dessas redes. Argumentam também que "Neste modelo de cooperação interorganizacional existe uma heterogeneidade de formas, geralmente caracterizadas pela figura do associativismo" (BALESTRIN; VERSCHOORE, 2008, p. 87). É muito comum as redes simétricas serem estruturadas como uma associação.

Já as redes formais são aquelas que possuem contratos para regular o relacionamento entre os participantes. Para Balestrin e Verschoore (2008, p. 87), "Nas redes formais, a gestão é estabelecida por regras claras, mediante cláusulas explícitas segundo as quais cada um dos atores terá seus direitos e deveres garantidos pela execução contratual".

As redes informais são consideradas redes de conivência, nas quais não há um contrato formal que contenha as regras do relacionamento entre os atores da rede. São relações que podem ocorrer entre empresas, organizações profissionais, instituições, universidades, associações, entre outros (BALESTRIN; VERSCHOORE, 2008).

As redes apresentam características diferentes, que são influenciadas pela cultura e pelos objetivos das empresas envolvidas: algumas apresentam maior integração e comprometimento da individualidade das empresas, outras menos.

Existem vários modelos de rede. Kwasnicka (2006) cita as Cadeias de Suprimentos, Franquias, Consórcio de Empresas, Arranjos Produtivos Locais e Clusters como redes de empresas.

Já Balestrin e Verschoore (2008) abordam as Redes de Fornecimento, os Consórcios e Redes Associativas como sendo redes de cooperação empresarial. A seguir, serão brevemente abordadas as redes associativas, configuração de rede 
muito comum de micro e pequenas empresas que se unem a fim de atingir objetivos comuns.

Para tratar sobre redes associativas, é importante definir o que é associação e quais são os princípios do associativismo. Para o Sebrae (2009, p. 8), "Associação, em um sentido amplo, é qualquer iniciativa formal ou informal que reúne pessoas físicas ou outras sociedades jurídicas com objetivos comuns, visando superar dificuldades e gerar benefícios para os seus associados".

As associações são uma maneira de pequenas empresas unirem esforços para a superação de dificuldades e geração de benefícios ao grupo, com o intuito de atingirem objetivos comuns.

Os princípios do associativismo, conforme o Sebrae (2009), são Adesão voluntária e livre; Gestão democrática pelos sócios; Participação econômica dos sócios; Autonomia e independência; Educação formação e informação; Interação; Interesse pela comunidade.

Esses princípios é que orientam a formação e gestão das associações e eles são muito importantes para o grupo envolvido, uma vez que seu objetivo é o sucesso coletivo para que todos os participantes obtenham vantagens com 0 relacionamento.

\footnotetext{
A atual ênfase no associativismo empresarial está na percepção de que dificuldades e oportunidades comuns podem ser superadas com a realização de ações colaborativas que possibilitem às empresas de pequeno porte aumentar sua escala mediante a formação de redes associativas (BALESTRIN; VERSCHOORE, 2008, p. 97).
}

Depreende-se que as associações possibilitam às pequenas empresas a formação de redes com o intuito de colaborar com os parceiros e assim superar mais facilmente as dificuldades e abrir um leque maior de oportunidades para as empresas associadas. 


\subsection{Redes de colaboração empresarial}

Empresas que se encontram no mesmo nível na cadeia de valor também se organizam em rede e cooperam para competir. Essas são redes de cooperação horizontais.

Redes horizontais se diferem de outros tipos de redes de cooperação, um aspecto distintivo importante é que as decisões são tomadas de forma conjunta, dificilmente há uma empresa que tenha mais poder na tomada de decisões, porém não é um entendimento unânime, alguns autores entendem que as decisões são mais centralizadas (SOARES et al, 2011).

"As redes reúnem empresas que possuem objetivos comuns, mantendo, no entanto, a independência e a individualidade de cada participante" (PARÉ, 2010, p. 99). A participação em uma rede colaborativa não faz com que as empresas percam sua individualidade, elas se unem a fim de atingir objetivos comuns.

\section{Em uma perspectiva estratégica, pode-se considerar a configuração em rede como meio para alcançar um fim. Desse modo, ao participar de uma rede, a empresa busca alcançar certos objetivos que dificilmente seriam alcançados de forma individualizada (BALESTRIN; VARGAS, 2004, p. 213).}

Na afirmação do autor, fica clara a importância da cooperação para essas redes, uma vez que as empresas se configuram em rede e cooperam a fim de atingir objetivos que sozinhas dificilmente alcançariam.

Porter (2009, p. 37) afirma que "As empresas precisam ser flexíveis para reagir com rapidez às mudanças competitivas e de mercado". No entendimento do autor, a flexibilidade é uma condição para as empresas acompanharem as rápidas mudanças do mercado.

As redes colaborativas são ambientes que, através de ações de colaboração, podem proporcionar às empresas um ambiente de maior flexibilidade e rápida absorção das mudanças. Sendo assim, representam uma oportunidade para as empresas que buscam esses atributos. 
Balestrin e Verschoore (2008, p. 152) entendem que "Dificilmente uma rede de cooperação sobreviverá ao longo do tempo se os interesses entre os atores participantes forem divergentes". Os objetivos das várias empresas participantes da rede são cruciais para que ela prospere e consiga sobreviver frente às dificuldades impostas pelo mercado, por isso a importância de os parceiros terem objetivos comuns e claros entre si.

Os relacionamentos envolvendo grandes empresas, principalmente no setor produtivo, já foram amplamente estudados, porém relacionamentos envolvendo pequenas empresas do setor varejista não são facilmente encontrados na literatura. Pacagnam (2006) chama a atenção para o fato de muitas pequenas empresas se espelharam em iniciativas do segmento industrial e passaram a se unir a fim de poder usufruir os benefícios das compras conjuntas. Essa foi a característica das primeiras redes.

Outras alianças estratégicas passaram a se estruturar com objetivos bem mais aprimorados, como a aquisição de conhecimento, informação e outras fontes que pudessem reverter em vantagem competitiva. O planejamento estratégico, assunto abordado a seguir, é uma ferramenta muito importante para as micro e pequenas empresas para a definição de estratégias que ampliem as vantagens competitivas.

\subsection{Planejamento estratégico}

O planejamento estratégico é uma ferramenta muito importante e pode ser decisiva na definição de estratégias para as empresas.

Antes de abordar a importância do planejamento estratégico para as micro e pequenas empresas, é importante definir o que é planejamento estratégico. Para Chiavenato e Sapiro (2009, p. 29), "O planejamento estratégico é um processo de formulação de estratégias organizacionais no qual se busca a inserção da organização e de sua missão no ambiente em que ela está atuando". 
Depreende-se que o processo de formulação de estratégias caracteriza-se como planejamento estratégico e, através dele, a empresa busca se integrar e ganhar força no ambiente no qual ela compete.

Planejamento estratégico é o processo administrativo que proporciona
sustentação metodológica para se estabelecer a melhor direção a ser
seguida pela empresa, visando ao otimizado grau de interação com os
fatores externos - não controláveis - atuando de forma inovadora e
diferenciada (OLIVEIRA, 2009, p. 17).

Através do planejamento estratégico, os empresários têm sustentação para tomar as decisões sobre qual a direção a ser seguida pela empresa, analisando fatores internos e externos à mesma. Por essa mesma via, os empresários têm capacidade de analisar o ambiente interno e externo das empresas e identificar maneiras de adquirir vantagens competitivas e as micro e pequenas empresas também podem se valer desta ferramenta para buscar maior competitividade.

Encontrar estratégias competitivas adequadas à realidade de cada empresa, que proporcionem tomadas de decisão apropriadas e garantam às empresas vantagens competitivas necessárias à sobrevivência e ao crescimento no mercado, é uma tarefa cada vez mais difícil (PARÉ, 2010). Assim, cada organização deve analisar seu ambiente interno e externo para formular estratégias que sejam compatíveis com o ambiente no qual estão inseridas.

Não basta planejar, é preciso conhecer o ambiente no qual se está competindo. Para Pacagnan (2006, p. 23), "O mais importante no planejamento estratégico de qualquer empresa é identificar onde ela pode agregar um maior valor ao seu produto, ou seja, onde pode adquirir vantagens competitivas".

Planejando, conhecendo a posição de sua empresa no mercado, as micro e pequenas empresas têm melhores condições para definir objetivos, bem como as estratégias para atingi-los. 


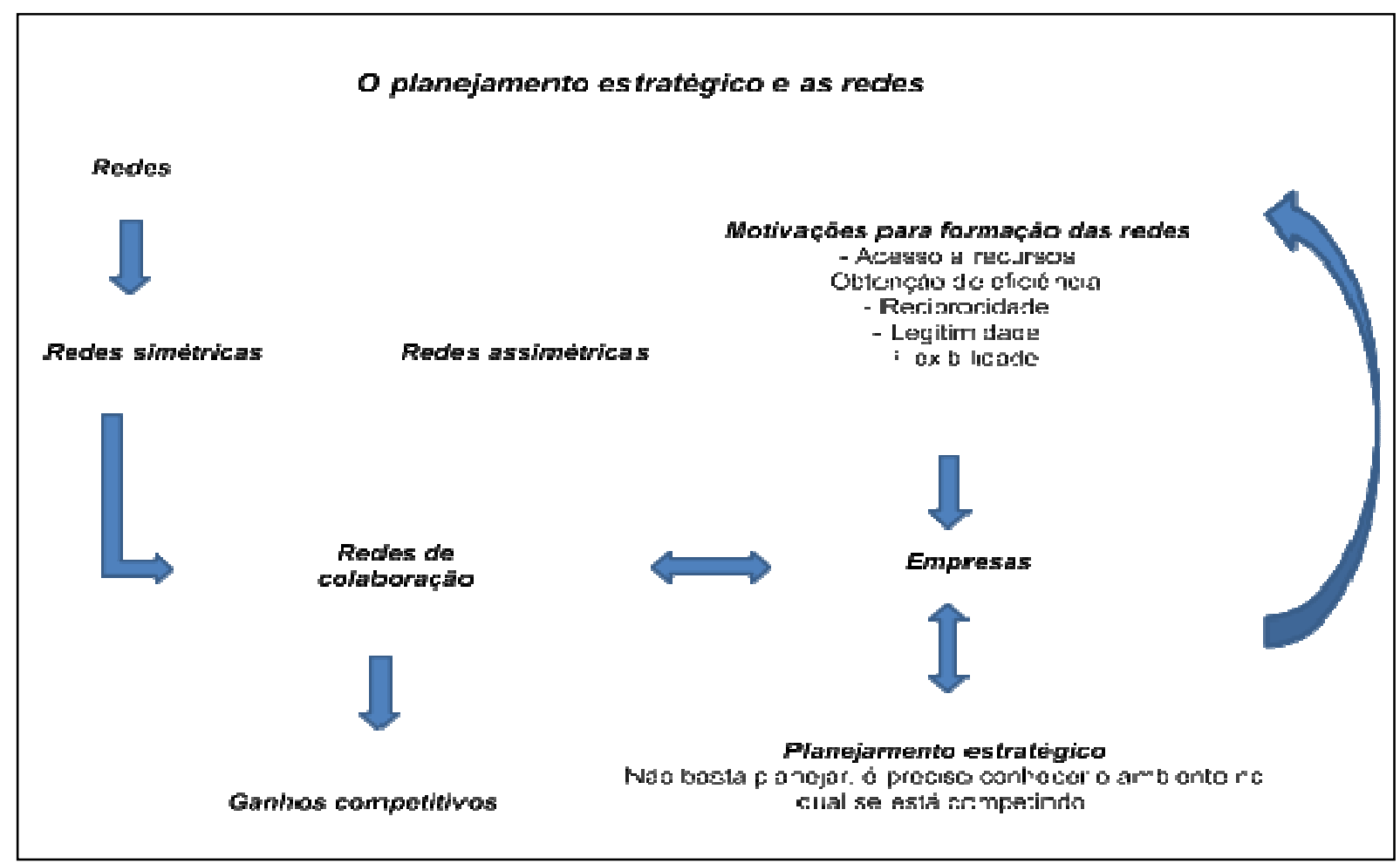

Figura 1 - $O$ planejamento estratégico e as redes Fonte: Elaborado pelos autores.

É muito importante que a empresa, ao ingressar na rede, tenha seus objetivos bem definidos e que estes atendam, na medida do possível, aos anseios de todos os participantes, ou seja, a definição dos objetivos estratégicos da rede deve ser realizada de forma participativa, a fim que todos os empresários possam se pronunciar.

Colaborar para competir é uma estratégia que vem sendo usada por muitas empresas que atuam nos mais diversos setores da economia. Sejam elas grandes, médias ou pequenas, o que há de comum entre elas é o fato de se aliarem a outras empresas para atingir objetivos que o grupo tem em comum.

Depreende-se que a estratégia busca atender aos objetivos estabelecidos para a empresa. Os autores argumentam, ainda, que a estratégia poderá requerer modificações, uma vez que condições ambientais e organizacionais sofrem mudanças. 
Através da estratégia competitiva, as empresas buscam se tornar mais competitivas no mercado. Para Porter (1989, p. 1), "A estratégia competitiva é a busca de uma posição competitiva favorável em uma indústria, a arena fundamental onde ocorre a concorrência".

Zaccarelli (1995) afirma que a prática da estratégia nas empresas certamente não será uniforme, pois cada uma terá suas peculiaridades. Entretanto, em todas elas a ênfase central será na administração das vantagens competitivas e da arquitetura estratégica. Para o autor, as vantagens competitivas devem ser trabalhadas a favor da empresa. As empresas não devem correr o risco de desperdiçar uma vantagem competitiva deixando de inovar.

As motivações para formação de redes podem surgir através do planejamento estratégico das empresas, quando os empresários percebem na rede uma oportunidade de atingir objetivos que dificilmente seriam alcançados individualmente.

2.5 Fatores que influenciam o desenvolvimento das redes e os ganhos competitivos das empresas que participam de redes colaborativas.

Para melhor esclarecer as motivações para a formação de redes, Balestrin e Verschoore (2008) descrevem os principais objetivos em comum que motivam essa formação.

\begin{tabular}{|l|l|}
\hline \multicolumn{1}{|c|}{ OBJETIVOS COMUNS } & \multicolumn{1}{c|}{ DEFINIÇÃO } \\
\hline Acessar recursos & Necessidade de acessar e compartilhar soluções e recursos. \\
\hline Exercer Assimetria & Necessidade de maior influência no mercado. \\
\hline Buscar reciprocidade & Necessidade de desenvolver ações coletivas de interesse comum. \\
\hline Ganhar eficiência & Necessidade de maior eficiência interna. \\
\hline Alcançar estabilidade & Necessidade de maior estabilidade frente à incerteza ambiental. \\
\hline Atingir legitimidade & Necessidade de ganhar legitimidade no mercado. \\
\hline Possibilitar flexibilidade & Necessidade de melhor adaptação aos ambientes mais dinâmicos \\
\hline
\end{tabular}

Quadro 1 - Objetivos comuns na formação das redes

Fonte: Balestrin e Verschoore (2008, p. 156)

Segundo os autores, esses são os principais objetivos pelos quais as empresas decidem cooperar e formar redes. As redes são formadas a fim de atingir 
um ou vários desses objetivos, por isso é muito importante que, ao entrar em uma rede, as empresas tenham seus objetivos bem definidos e busquem conhecer os objetivos da rede para analisar se essa é a melhor estratégia para a empresa, se junto a essa rede a empresa irá atingir seus objetivos individuais.

As empresas motivam-se para a formação de redes por objetivos que têm em comum. Ao participar das redes, passam a obter ganhos competitivos também relacionados por Balestrin Verschoore (2008). Conforme os autores, através do primeiro ganho competitivo, maior escala e poder de mercado, as empresas envolvidas melhoram a capacidade de ação por meio da união com outras empresas e ainda ampliam sua capacidade de atrair parcerias e novos negócios.

Quando as empresas atuam individualmente, da mesma forma procuram as soluções para os problemas, diferentemente ocorre com empresas que participam de redes. Segundo Balestrin e Verschoore (2008), ao atuar em rede, parte dos problemas podem ser superados com soluções que partem da rede.

Essas soluções podem ser chamadas de soluções coletivas, descritas como o segundo ganho competitivo por Balestrin e Verschoore (2008). Dentre elas, pode-se citar o acesso ao crédito, acesso a novas tecnologias, a serviços contábeis, entre outras, porém essas também dependem dos objetivos traçados pela rede, uma vez que estas possuem características e ainda possíveis soluções bastante particulares, diretamente relacionadas aos objetivos da rede, para oferecer aos associados.

O terceiro ganho competitivo apresentado pelos autores é a redução de custos e riscos. Na cooperação em rede, pode-se dizer que as empresas diminuem seus custos e riscos. Para Balestrin e Verschoore (2008, p. 123), "Entre outros motivos, os ganhos ocorrem porque uma empresa que participa de uma rede de cooperação é capaz de captar as fontes de eficiência das demais empresas associadas, benefícios que os competidores externos não podem obter".

Balestrin e Verschoore (2008, p. 124) argumentam que, em estudos de caso realizados anteriormente, "[...] a união entre empresas resultou na diminuição do custo na taxa de telefonia, do material de expediente e dos valores de seguros, além de viabilizar a diluição do risco nas ações de marketing e comunicação". 
A rede, através de negociações e parcerias, consegue negociar taxas menores com as empresas que fornecem tais serviços aos associados da rede.

Outro ganho obtido pelas empresas é o acúmulo de capital social. As empresas, através de ações conjuntas, têm maior capacidade de gerar capital social, contudo é importante destacar que isso ocorrerá dependendo em muito do grau de cooperação que envolve as empresas.

Putnam (1995, apud DUCCI; TEIXEIRA) define capital social como sendo as características da organização social, tais como redes, normas e confiança social, que facilitam a coordenação e a cooperação em benefício mútuo.

O acúmulo de capital social pode ser entendido como relações entre indivíduos, e traz inúmeras oportunidades de negócios para as empresas, uma vez que amplia o relacionamento com as demais organizações.

Conhecimento e aprendizagem coletivos também são apresentados por Balestrin e Verschoore (2008) como ganhos competitivos, porém recebem muito mais destaque, uma vez que têm um alto grau de importância para as organizações e redes.

As redes de colaboração também são ambientes que proporcionam conhecimento e aprendizagem aos envolvidos. "Conhecimento organizacional é definido como um estado ou propriedade de uma organização, oriundo de um processo de aprendizagem resultante de experiências passadas e da adaptação de um ambiente" (NAKANO, 2005, p. 56).

A comunicação existente entre os indivíduos envolvidos na organização ou rede é que possibilita a criação de conhecimento. Quando se fala em construção de conhecimento entre indivíduos, é importante destacar a confiança, que é relacionada por Nakano (2005) como um fator facilitador do fluxo de informações em uma rede. Depreende-se que quanto maior a confiança existente entre os indivíduos melhor será a comunicação entre as empresas envolvidas.

Balestrin e Verschoore (2008) entendem que os canais de informação das redes de cooperação proporcionam acesso rápido às novas tecnologias e possibilitam o desenvolvimento de estratégias coletivas para a inovação. 
Os autores argumentam que uma rede, por si só, não é um ambiente de geração de aprendizado. Para que efetivamente a rede favoreça a inovação para as empresas associadas, existem algumas condições viabilizadoras que, segundo eles, são: "relação de confiança entre os empresários, estrutura descentralizada e menos hierárquica, comunicação informal, existência de espaços e momentos que possibilitem a socialização de conhecimentos e o acesso a novos conhecimentos e competências externas" (BALESTRIN; VERSCHOORE 2008, p. 143).

Para que as redes possibilitem ganhos competitivos para as empresas, é necessário um conjunto de fatores: boa comunicação, relação de confiança e uma estrutura descentralizada. Esses fatores podem ser observados na figura 2.

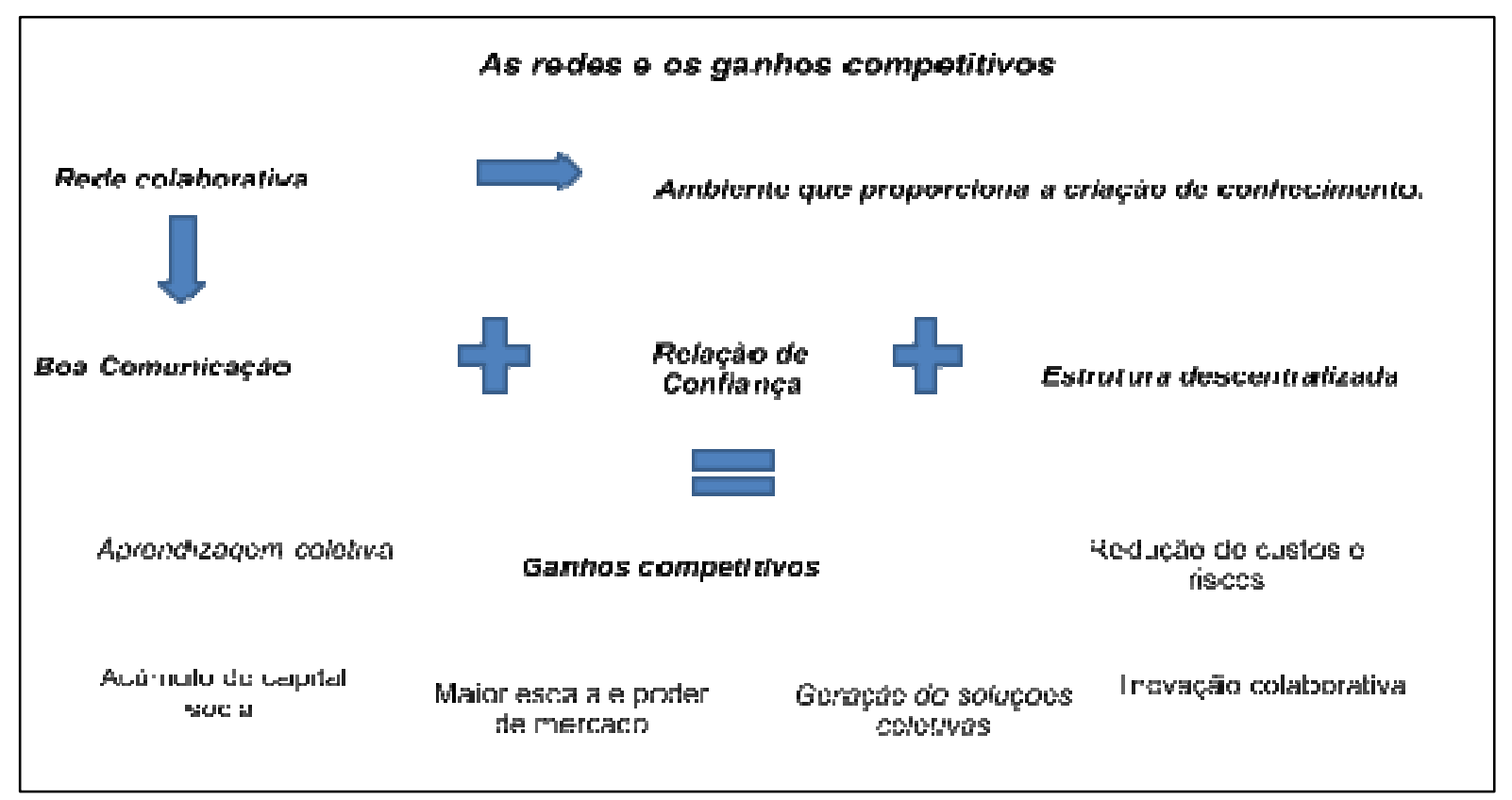

Figura 2 - As redes e os ganhos competitivos

Fonte: elaborado pelos autores.

\section{Metodologia}

Para compor o referencial teórico, foi realizada uma pesquisa bibliográfica, na qual foram utilizados vários tipos de publicações. O método de abordagem da 
pesquisa é dedutivo, que, para Oliveira (2001, p. 62), "[...] procura transformar enunciados complexos, universais, em particulares".

A pesquisa foi realizada através de um estudo de caso coletivo, no qual foram pesquisadas várias empresas que têm características em comum. $O$ universo da pesquisa é composto pelos empresários do ramo varejista que participam redes colaborativas na cidade de Três Coroas, no Estado do Rio Grande do Sul. Sendo o universo pequeno buscou-se que ele, no todo, formasse a amostra.

Participaram da pesquisa sete empresários que responderam a um questionário que continha 15 itens, nos quais os empresários marcavam um dos cinco itens: concordo plenamente, concordo, indiferente, discordo, discordo plenamente.

A pesquisa caracteriza-se como quantitativa, uma vez que se buscou quantificar as opiniões dos empresários pesquisados. Para a análise dos dados, utilizou-se a estatística simples.

\section{Análise dos resultados}

O questionário aplicado é composto por 15 itens que buscam identificar a percepção dos empresários quanto às redes em que atuam e em relação à importância do planejamento estratégico para as empresas em questão. Os itens que apresentaram mais relevância para os resultados dessa pesquisa dizem respeito ao planejamento estratégico, às vantagens dos associados em participar da rede e em relação à percepção dos empresários quanto às redes das quais participam.

Pode-se observar no Gráfico 2 que, quanto à participação na rede, 100\% dos empresários entendem como uma estratégia para micro e pequenas empresas. 


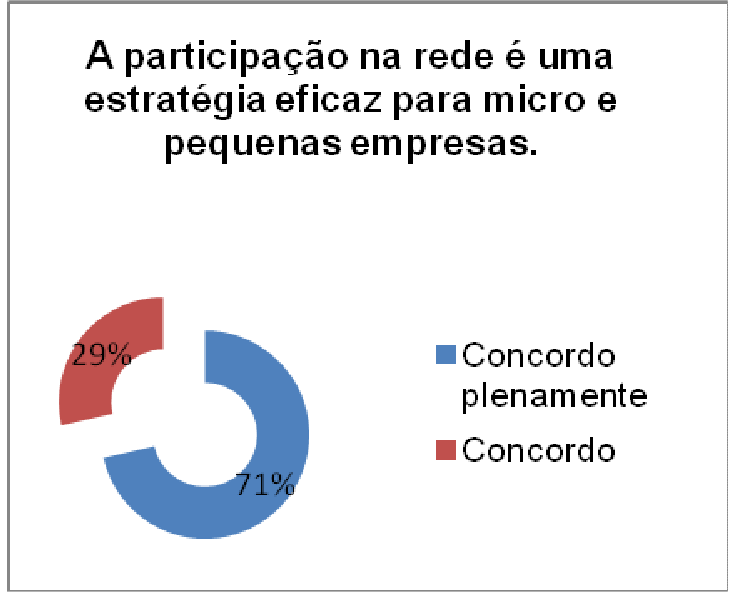

Gráfico 2 - Rede estratégia para MPEs

Fonte: Pesquisa realizada pelos autores (2012).

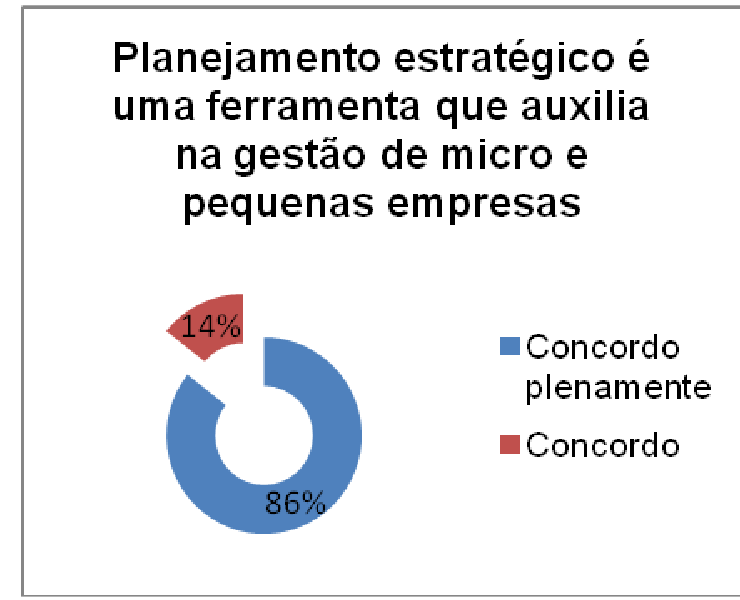

Gráfico 3 - Planejamento estratégico

Fonte: Pesquisa realizada pelos autores (2012)

No Gráfico 3 fica evidenciada a importância do planejamento estratégico para essas empresas. Mais de $85 \%$ dos empresários concordam plenamente que o planejamento estratégico é uma ferramenta que auxilia na gestão.

A relevância das compras coletivas fica evidenciada no Gráfico 4, uma vez que as compras coletivas foram o objetivo que motivou a formação das primeiras redes de micro e pequenas empresas varejistas.

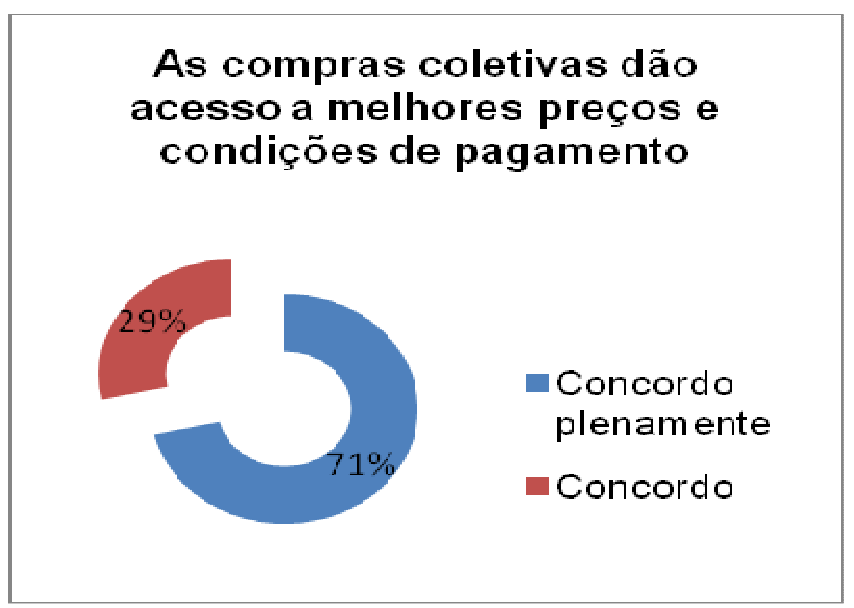

Gráfico 4 - compras coletivas

Fonte: Pesquisa realizada pelos autores (2012) 
Pode-se observar que $100 \%$ dos empresários concordam plenamente que as compras coletivas dão acesso a melhores preços e condições de pagamento.

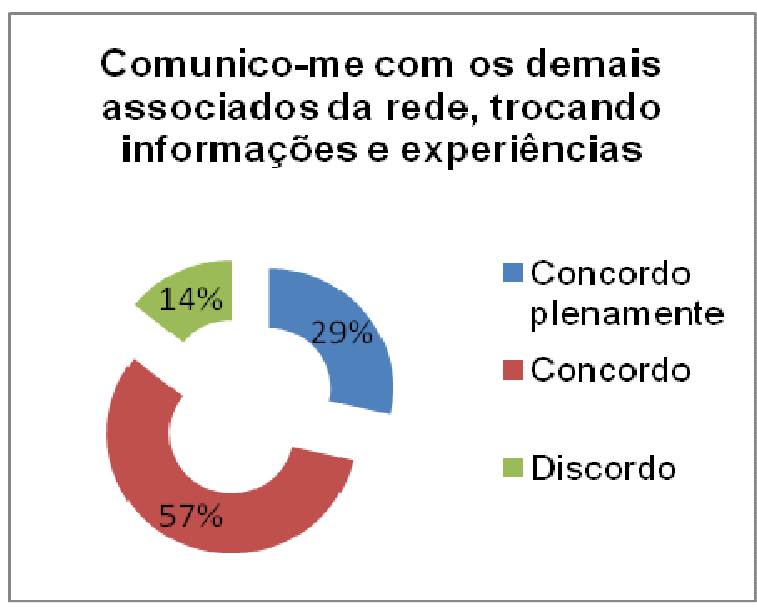

Gráfico 5 - Comunicação

Fonte: Pesquisa realizada pelos autores (2012)

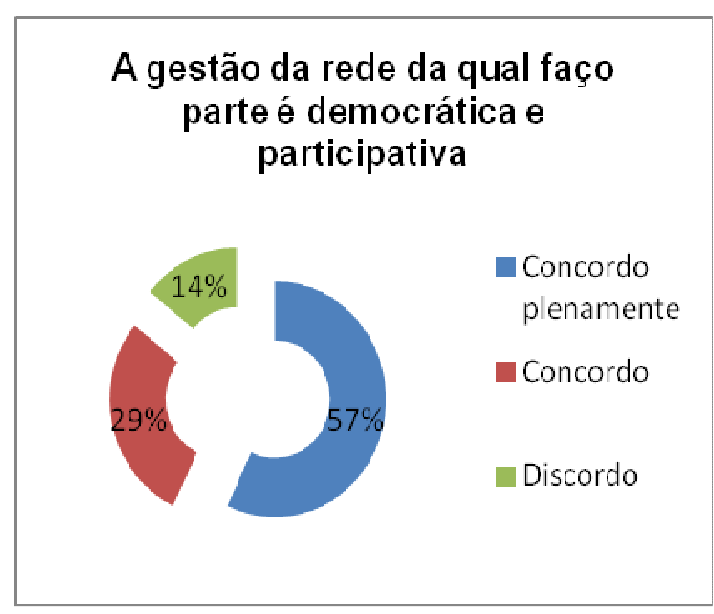

Gráfico 6 - Gestão

Fonte: Pesquisa realizada pelos autores (2012)
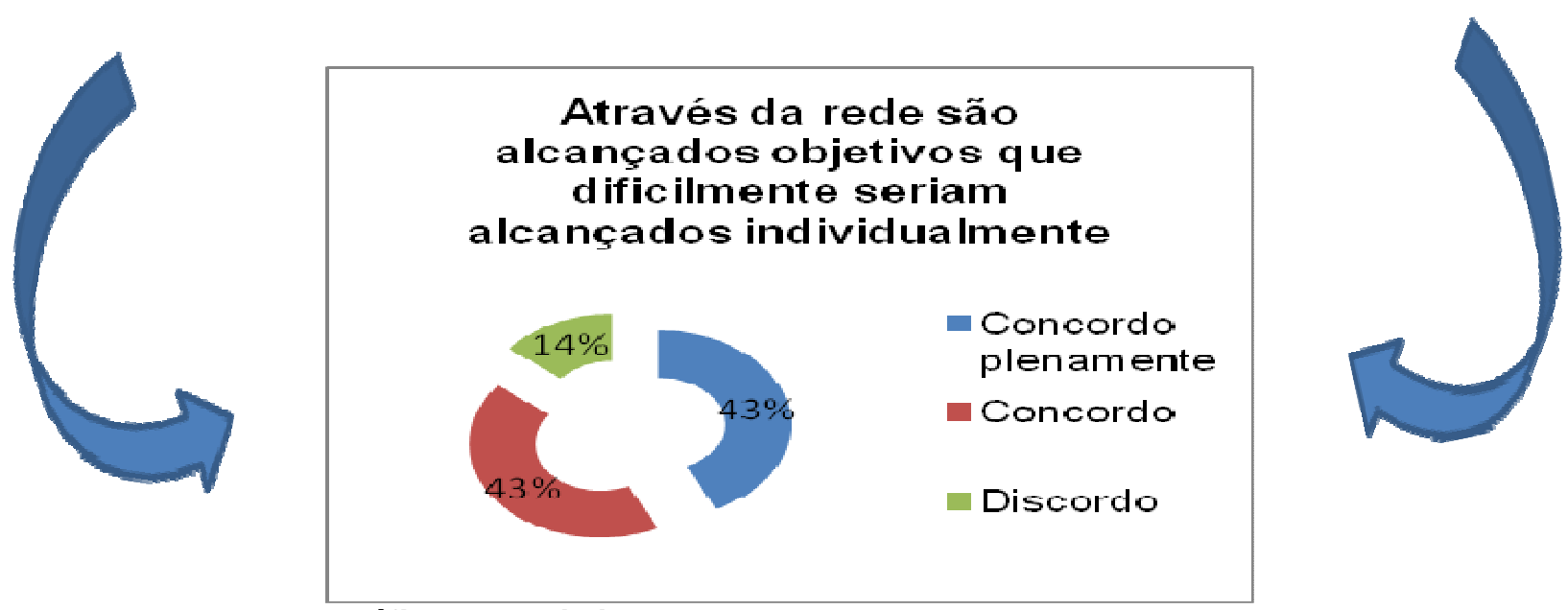

Gráfico 7 - Objetivos

Fonte: Pesquisa realizada pelos autores (2012)

Essa relação ficou comprovada na pesquisa, uma vez que a mesma empresa não percebe uma boa comunicação na rede, não entende a gestão como democrática e participativa e, em consequência, entende ter atingido objetivos através da rede; as outras empresas que perceberam boa comunicação e a gestão da rede como sendo democrática também atingiram os objetivos. 
É importante destacar também a importância da confiança nessa relação, uma vez que a confiança possibilita uma boa comunicação, fazendo com que ocorra a criação de conhecimento entre os membros das redes.

Ainda se pode observar, na pesquisa, que a participação em uma rede colaborativa possibilita às empresas alavancar os resultados, conforme se observa no Gráfico 8.

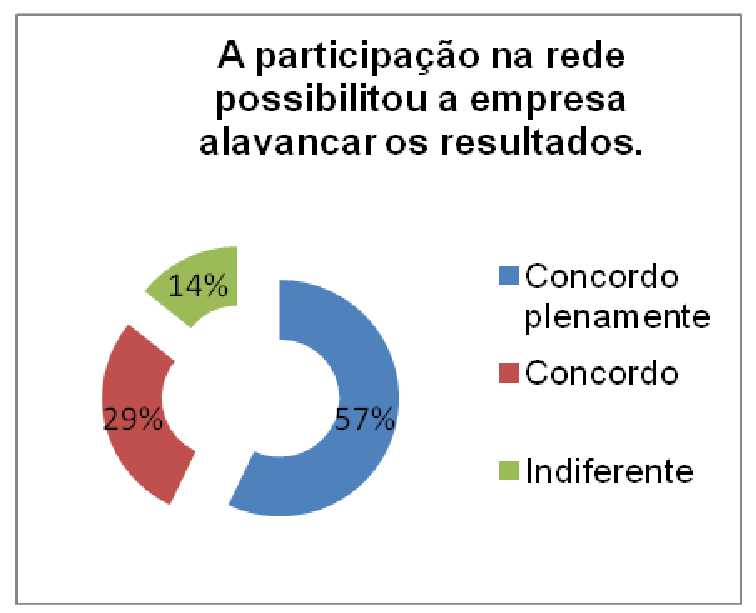

Gráfico 8 - Resultados

Fonte: Pesquisa realizada pelos autores (2012)

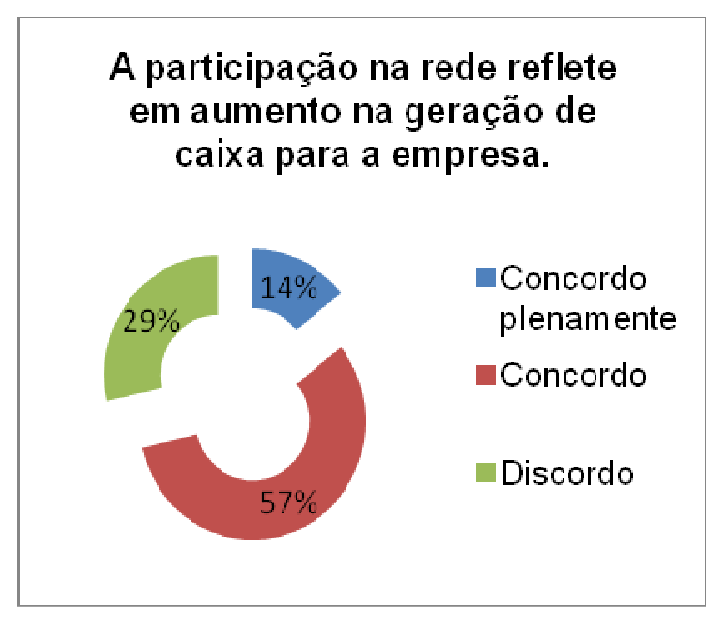

Gráfico 9 - Geração de caixa

Fonte: Pesquisa realizada pelos autores (2012)

A pesquisa demonstrou também que mais de $80 \%$ dos empresários entendem que a rede proporciona um aumento no volume de vendas para as empresas. Quanto à geração de caixa, mais de $70 \%$ dos empresários entendem que a rede possibilita maior geração de caixa para as empresas.

\section{Conclusões}

Buscou-se, neste artigo, analisar o processo de planejamento estratégico para as micros e pequenas empresas que atuam em alianças ou redes na cidade de Três Coroas no Rio Grande do Sul.

A tecnologia desencadeou muitas mudanças no mercado, acelerou 0 processo de globalização, encurtou distâncias e aumentou a concorrência, uma vez 
que as empresas passaram a concorrer também com organizações que comercializam por meio virtual.

As grandes redes em busca de captar mais clientes, instalam filiais em pequenas cidades, como é o caso de Três Coroas, onde se encontram filias de grandes redes varejistas.

As micro e pequenas empresas enfrentam muitas dificuldades, pois a mão de obra contratada muitas vezes não é qualificada, o acesso às novas tecnologias é difícil, não têm poder de barganha junto aos fornecedores por comprar em pequenas quantidades. Assim, competir com grandes empresas passa a ser um desafio para esses pequenos empresários.

A cooperação, apesar de muito antiga, é uma novidade como forma de competir no meio empresarial. Ela surge como uma solução eficaz para micro e pequenas empresas que se unem para atingir objetivos comuns, abrindo mão de um pouco de sua individualidade em benefício do conjunto.

A formação de redes colaborativas por micro e pequenas empresas possibilita a elas a operação de várias ações conjuntas, sem perder a autonomia de cada uma, o que thes condiciona competir com maior igualdade com as grandes empresas.

Através da pesquisa bibliográfica, foi possível compreender as diversas tipologias de redes existentes e suas configurações. As redes colaborativas podem ser caracterizadas como redes simétricas, uma vez que as decisões são tomadas em conjunto, e também são redes horizontais, pois as empresas estão no mesmo nível na cadeia de valor. Observa-se que algumas redes colaborativas possuem um grau de formalidade maior que outras, dependendo dos objetivos das empresas.

As empresas participantes da pesquisa, em sua maioria, fazem parte de redes formadas juridicamente como associações. Na associação, várias ações são coordenadas conjuntamente em favor da classe, nesse caso, os comerciantes.

Através da pesquisa, verificou-se que a participação em uma rede colaborativa é uma estratégia para micro e pequenas empresas varejistas. Quanto ao planejamento estratégico, percebe-se que os empresários analisam o ambiente no qual estão inseridos, o que é muito importante para a gestão da empresa. 
Ao participar das redes, os empresários perceberam vários benefícios para as suas empresas. Um aspecto considerado em unanimidade como uma vantagem para as empresas foram as compras coletivas, que são consideradas pela literatura como uma das principais motivações para a formação de redes, uma vez que possibilita às empresas maior poder de barganha, acesso a melhores preços e condições de pagamento.

A gestão estratégica para as micro e pequenas empresas que participam de alianças ou redes é muito importante, uma vez que a rede é mais um ambiente no qual estão inseridas, em que há novos relacionamentos a serem gerenciados. A pesquisa demonstrou que a maioria dos empresários não enfrenta dificuldades em relação à comunicação com os demais associados.

O bom relacionamento entre as empresas associadas é um fator que pode desencadear no melhor desempenho da rede, pois para que as empresas venham a obter vantagens e atingir objetivos através da parceria é preciso que alinhem seus objetivos aos da rede. O que condiciona isso é uma boa comunicação e uma gestão participativa da rede.

As redes colaborativas são caracterizadas por sua gestão ser participativa, na qual todos os associados participam da definição de estratégias e tomadas de decisão. A confiança é um aspecto muito importante, pois se os empresários tiverem entre si uma relação de confiança, a comunicação será de melhor qualidade, possibilitando troca de experiências e informações entre os participantes da rede, contribuindo, assim, para a criação de conhecimento e inovação na rede.

Através das redes colaborativas, as empresas obtêm ganhos competitivos, que são relacionados com os objetivos das empresas que formam a rede e com o planejamento estratégico dessas empresas. Para atingir ganhos competitivos, é essencial uma boa comunicação, uma relação de confiança e uma estrutura descentralizada da rede.

As redes mostram-se como uma alternativa competitiva para micro e pequenas empresas, pois favorecem o fortalecimento dessa categoria que através da rede internaliza conhecimentos. As redes colaborativas não são vantajosas 
somente às empresas participantes: são importantes também aos funcionários dessas empresas, que, muitas vezes, têm acesso facilitado à qualificação. As cidades onde as empresas se localizam também se beneficiam com mais empregos para a população e geração de impostos aos municípios.

\section{Referências}

AMATO NETO, João. Redes de Cooperação Produtiva e Clusters Regionais: Oportunidades para Pequenas e Médias Empresas. São Paulo: Atlas, 2000.

BALESTRIN, Alsones; VARGAS, Lília Maria. A Dimensão Estratégica das Redes Horizontais de PMEs: Teorizações e Evidências. RAC, Rio de Janeiro, 2004. Edição Especial. Disponível em: <www.scielo.br/pdf/rac/v8nspe/v8nespa11.pdf >. Acesso em: 20 abr. 2012.

BALESTRIN, Alsones; VERSCHOORE; Jorge. Redes de cooperação empresarial: Estratégias de gestão na nova economia. Porto Alegre: Bookman, 2008.

CASTELLS, Manuel. A sociedade em Rede: A Era da Informação: Economia, Sociedade e Cultura. São Paulo: Paz e Terra, 2005.

CHIAVENATO, Idalberto; SAPIRO, Arão. Planejamento Estratégico: Fundamentos e aplicações. 2. ed. Rio de Janeiro: Elsevier, 2009.

CRAVENS, David W.; PIERCY, Nigel F. Marketing Estratégico. São Paulo: McGraw-Hill, 2007.

DUCCI, Norma Pimenta Cirilo; TEIXEIRA, Rivanda Meira. As redes sociais dos empreendedores na formação do capital social: um estudo de casos múltiplos em municípios do norte pioneiro no estado do Paraná. Cad. EBAPE.BR, (online) v. 9, no 4 Dez. 2011. Disponível em: <http://www.scielo.br/pdf/cebape/v9n4/03.pdf>. Acesso em: 15 out. 2012.

EIRIZ, Vasco. Proposta de Tipologia sobre Alianças Estratégicas. RAC, Rio de Janeiro, v. 5, n. 2, p. 65-90, 2001. Disponível em:

<http://www.scielo.br/pdf/rac/v5n2/v5n2a04.pdf>. Acesso em: 20 jul. 2012.

INSTITUTO BRASILEIRO DE GEOGRAFIA E ESTATÍSTICA - IBGE. Pesquisa anual do comércio. Rio de Janeiro. Disponível em: <www.ibge.gov.br>. Acesso em: 15 ago. 2012. 
KWASNICKA, Eunice Lacava. Em direção a uma teoria sobre redes de negócios. In: BOAVENTURA, João Maurício Gama (Org.). Rede de Negócios: Tópicos em Estratégia. São Paulo: Sant Paul, 2006.

LAGO, Adriano; SILVA, Tania Nunes da. Fatores condicionantes do desenvolvimento de relacionamentos intercooperativos na cooperativismo agropecuário. Porto Alegre: Sescoop RS, 2009.

MINTZBERG, Henry; QUINN, James Brian Quinn. O processo da Estratégia. 3. ed. Porto Alegre: Bookman, 2001.

NAKANO, Davi Noboru. Fluxos de conhecimento em redes interorganizacionais: conceitos e fatores de influência. In: AMATO NETO, João (Org.). Redes entre organizações. São Paulo: Atlas, 2005.

OLIVEIRA, Djalma de Pinho Rebouças de. Planejamento Estratégico. 26. ed. São Paulo: Atlas, 2009.

OLIVEIRA, Sílvio Luiz de. Tratado de Metodologia Científica. São Paulo: Pioneira Thomson Learning, 2001.

PACAGNAN, Mario Nei. Alianças estratégicas e redes colaborativas como alternativa competitiva para o pequeno varejista: um estudo comparado. Revista de Gestão USP, São Paulo, v. 13, n. especial, p. 19-30, 2006. Disponível em: $<$ http://www.ead.fea.usp.br/semead/9semead/resultado_semead/trabalhosPDF/454. pdf>. Acesso em: 14 abr. 2012.

PARÉ, Abel Moreira. Intercooperação: a formação de redes flexíveis como estratégia competitiva inteligente. Porto Alegre: Sescoop-RS, 2010.

PORTER, Michael E. Competição. Rio de Janeiro: Elsiever, 2009.

Estratégia Competitiva - Técnicas para análise de indústrias e da concorrência. Rio de Janeiro: Campus, 1989.

SERVIÇO BRASILEIRO DE APOIO ÀS MICROS E PEQUENAS EMPRESAS. SEBRAE. Anuário do trabalho na micro e pequena empresa. Brasília: DIEESE, 2011. Disponível em: <http://www.biblioteca.sebrae.com.br/bds/bds.nsf/572C3CE47 D9997DC83257486004E858E/\$File/NT00038B0A.pdf>. Acesso em: 5 set. 2012.

Associação: série empreendimentos coletivos. Brasília: SEBRAE, 2009.

SOARES, Ari de Souza et al. Benefícios Competitivos e conflitos em rede horizontal do setor supermercadista. REAd, Porto Alegre, ed. 69, v. 17, n. 2, p. 530-559, 2011. Disponível em: <http://www.scielo.br/scielo.php?pid=S141323112011000200009\&script=sci_abstract\&tlng=pt>. Acesso em: 2 ago. 2012. 
WITTMANN, Milton Lui; DOTTO, Dalva Righi; WEGNER, Douglas. Redes de empresas: um estudo de redes de cooperação do Vale do Rio Pardo e Taquari no Estado do Rio Grande do Sul. Redes, Santa Cruz do Sul, v. 13, n. 1, p. 160-180, jan./abr. 2008. Disponível em: <online.unisc.br/seer/index.php/redes>. Acesso em: 15 abr. 2012.

ZACCARELLI, Sérgio Baptista. A moderna estratégia nas empresas e o velho planejamento estratégico. RAE Light, São Paulo, v. 2, n. 5, 1995. Disponível em: <http://rae.fgv.br/rae/vol35-num5-1995/moderna-estrategia-nas-empresas-velhoplanejamento-estrategico >. Acesso em: 16 out. 2012. 